\title{
Hubungan Merokok, Minum Kopi dan Stress dengan Kejadian Hipertensi pada Pasien Rawat Jalan di Puskesmas Negeri Baru Kabupaten Way Kanan Tahun 2019
}

\author{
Relationship Smoking, Drinking Coffee and Stress with Hypertension in \\ Outpatients at The Public Health Center Negeri Baru in Way Kanan \\ Regency In 2019
}

\author{
Elva Nuryanti ${ }^{1}$, Khoidar Amirus ${ }^{2}$, Nurul Aryastuti ${ }^{2}$ \\ ${ }^{1}$ Puskesmas Negeri Baru Kabupaten Way Kanan, Lampung, Indonesia \\ 2 Fakultas Kesehatan Masyarakat Universitas Muhammadiyah, Lampung, \\ Indonesia \\ *Korespondensi penulis: elvanuryanti80@gmail.com
}

Penyerahan: 04-04-2020, Perbaikan: 24-04-2020, Diterima: 16-05-2020

\begin{abstract}
Hypertension is often referred to as a dark therapy (silent killer). The prevalence of population with national high blood pressure is 30.9\%. Whereas in Lampung Province primary hypertension or hypertension with unknown causes was (30\%) and other hypertension was (17\%). in Way Kanan Regency, third, (58.66\%). This study discusses the relationship smoking, drinking coffee and stress with hypertension in outpatients at the Negeri Baru Public Health Center in Way Kanan Regency in 2019. This type of quantitative research is analytic and cross sectional analytic design. The population and sample of all outpatients who did the examination were 128 people with accidental sampling technique. Test data analysis used in this study using the Chi-Square test. The results of the study found that most of them solved hypertension as many as 71 respondents (55.5\%). Most of the smoking behavior as many as 78 respondents (60.9\%). Coffee consumption, most coffee drinkers were 83 respondents (64.8\%). Most outpatients increased stress by 67 respondents (52.3\%). There is a relationship of smoking with the incidence of hypertension, obtained $p$ value $(0,000<a 0.05)$. OR: 17,653 . There is a relationship of coffee drinking with the incidence of hypertension, obtained $p$ value $(0,000<a 0.05)$. OR: 6,760. There is a relationship of stress with the incidence of hypertension, obtained $p$ value $(0,000<a 0.05)$. OR: 9,666. Freed for respondents who consume coffee in order to reduce coffee consumption by reducing the dose or dose of coffee. More for respondents who smoke to reduce the number of cigarettes spent gradually. For respondents who are trying to restore health for the sake of routine.
\end{abstract}

Keywords: Consuming Coffee, Stress, Hypertension.

\begin{abstract}
ABSTRAK
Hipertensi sering kali disebut sebagai pembunuh gelap (silent killer). Prevalensi penduduk dengan tekanan darah tinggi secara nasional sebesar 30,9\%. Sedangkan di Provinsi Lampung hipertensi essensial primer atau hipertensi dengan penyebab tidak diketahui sebesar (30\%) dan hipertensi lainnya sebesar (17\%). Kabupaten Way Kanan menempati urutan ketiga yaitu, sebesar $(58,66 \%)$. Penelitian ini bertujuan mengetahui hubungan merokok, minum kopi dan stress dengan kejadian hipertensi pada pasien rawat jalan di Puskesmas Negeri Baru Kabupaten Way Kanan Tahun 2019. Jenis penelitian kuantitatif dengan desain analitik dan pendekatan cross sectional. Populasi dan sampel seluruh pasien rawat jalan yang melakukan pemeriksaan sebanyak 128 orang dengan teknik accidental sampling. Uji analisis data yang digunakan pada penelitian ini
\end{abstract}

Jurnal Dunia Kesmas, Vol. 9 No. 2, April 2020, hal. 235 - 244

ISSN 2301-6604 (Print), ISSN 2549-3485 (Online)

http://ejurnalmalahayati.ac.id/index.php/duniakesmas/index 
menggunakan uji Chi-Square. Hasil penelitian diketahui sebagian besar mengalami hipertensi sebanyak 71 responden $(55,5 \%)$. Merokok sebagian besar merokok sebanyak 78 responden $(60,9 \%)$. konsumsi kopi, sebagian besar peminum kopi sebanyak 83 responden $(64,8 \%)$. Sebagian besar pasien rawat jalan mengalami stress sebanyak 67 responden $(52,3 \%)$. Ada hubungan merokok dengan kejadian hipertensi, diperoleh $\mathrm{p}$ value $(0,000<a$ 0,05). OR: 17,653. Ada hubungan minum kopi dengan kejadian hipertensi, diperoleh $p$-value $(0,000<a 0,05)$. OR: 6,760. Ada hubungan stress dengan kejadian hipertensi, diperoleh p-value $(0,000<a \quad 0,05)$. OR: 9,966. Disarankan responden agar mengurangi konsumsi kopi dengan cara mengurangi takaran kopi dan gula. Serta disarankan bagi responden yang merokok untuk mengurangi jumlah rokok yang dihisap secara bertahap. Bagi responden yang mengalami stres sebaiknya untuk memeriksakan kesehatan secara rutin.

Kata kunci: Merokok, Minum Kopi, Stres, Hipertensi.

\section{PENDAHULUAN}

Hipertensi sering kali disebut sebagai pembunuh gelap (silent killer) karena termasuk yang mematikan tanpa disertai dengan gejala-gejalanya lebih dahulu sebagai peringatan bagi korbannya. Hipertensi adalah tekanan darah sistolik melebihi $140 \mathrm{mmHg}$ dan tekanan darah diastolik melebihi 90 $\mathrm{mmHg}$ tekanan diastolik pada seseorang yang tidak sedang menggunakan obat anti hipertensi (Wijayaningsih, 2013).

Sampai saat ini, hipertensi masih merupakan tantangan besar di Indonesia.. Menurut American Heart Association ( $A H A)$, penduduk Amerika yang berusia diatas 20 tahun menderita hipertensi telah mencapai angka hingga 74,5 juta jiwa, namun hampir sekitar 90-95\% kasus tidak diketahui penyebabnya. Hipertensi merupakan silent killer dimana gejala dapat bervariasi pada masing-masing individu dan hampir sama dengan gejala penyakit lainnya. Gejalagejalanya itu adalah sakit kepala/rasa berat di tengkuk, mumet (vertigo), jantung berdebar-debar, mudah lelah, penglihatan kabur, telinga berdenging (tinnitus), dan mimisan (Kemenkes. RI, 2014).

Prevalensi penduduk dengan tekanan darah tinggi secara nasional sebesar 30,9\%. Prevalensi tekanan darah tinggi pada perempuan $(32,9 \%)$ lebih tinggi dibanding dengan laki-laki
$(28,7 \%)$. Prevalensi di perkotaan sedikit lebih tinggi $(31,7 \%)$ dibandingkan dengan perdesaan $(30,2 \%)$. Prevalensi semakin meningkat seiring dengan pertambahan umur (Kemenkes. RI, 2018).

Sedangkan di Provinsi Lampung hiperetnsi essensial primer atau hipertensi dengan penyebab tidak diketahui sebesar $(30 \%)$ dan hipertensi lainnya sebesar (17\%). Prevalensi hipertensi di Provinsi Lampung berdasarkan cakupan pengukuran tekanan darah penduduk usia $\geq 18$ tahun menurut jenis kelamin pada laki-laki sebanyak 32.757 $(21,87 \%)$, dan perempuan sebanyak $51.591 \quad(16,28 \%)$. Prevalensi hipertensi di Provinsi Lampung, tertinggi di Kabupaten Tulang Bawang dan terendah di Kota Metro, di Kabupaten Way Kanan menempati urutan ketiga yaitu, sebesar $(58,66 \%)$ angka ini lebih tinggi jika dibandingkan dengan kabupaten Pringsewu $(6,12 \%)$ dan Kabupeten Pesawaran (7,75\%) (Dinas Kesehatan Provinsi Lampung, 2017).

Banyak faktor yang berperan untuk terjadinya hipertensi meliputi faktor risiko yang tidak dapat dikendalikan (mayor) dan faktor risiko yang dapat dikendalikan (minor). Faktor risiko yang tidak dapat dikendalikan (mayor) seperti keturunan, jenis kelamin, ras dan umur. Sedangkan faktor risiko 
yang dapat dikendalikan (minor) yaitu olahraga, makanan (kebiasaan makan garam), merokok, alkohol, stres, kelebihan berat badan (obesitas), kehamilan dan penggunaan pil kontrasepsi (Muhammadun, 2010).

Penelitian yang dilakukan Manggopa., Ratag., Kandou (2017). Tentang hubungan kebiasaan merokok dan stres dengan kejadian penyakit hipertensi di Desa Tarabitan Kecamatan Likupang Barat Kabupaten Minahasa Utara. Hasil uji statistik menunjukan bahwa terdapat hubungan antara kebiasaan merokok dengan kejadian hipertensi $(p=0,000)$ dan terdapat hubungan antara stress dengan kejadian hipertensi $(p=0,000)$. Sedangkan di Puskesmas Negeri Baru Kabupaten Way Kanan prevelansi kejadian hipertensi pada tahun 2016 sebanyak 250 penderita (5,39\%) dan meningkat pada tahun 2017 sebanyak $267(6,07 \%)$ penderita pada tahun 2018 sebanyak $174 \quad(4,82 \%)$ penderita. Berdasarkan pra survey pada Januari 2019 dengan melakukan wawancara terhadap 20 pasien hipertensi di Puskesmas Negeri Baru Kabupaten Way Kanan diketahui terdapat $(30 \%)$ tekanan darahnya stabil dalam tiga bulan terakhir. Sedangkan perilaku merokok sebanyak $(70 \%)$ dengan kebiasaan merokok $>20$ batang perhari dan (80\%) diantaranya memiliki kebiasaan minum kopi 1-2 gelas sehari, selain itu juga (60\%) diantaranya mengatakan khawatir akan penyakit yang dialami dikarenakan tidak kunjung sembuh. Berdasarkan latar belakang dan dan fenomena diatas maka peneliti tertarik untuk melakukan penelitian tentang hubungan merokok, minum kopi dan stress dengan kejadian hipertensi pada pasien rawat jalan di Puskesmas Negeri Baru Kabupaten Way Kanan Tahun 2019.

\section{METODE}

Jenis penelitian yang digunakan dalam penelitian ini menggunakan penelitian analitik dengan menggunakan pendekatan cross sectional mengenai hubungan merokok, konsumsi kopi dan stres dengan terjadinya hipertensi, dengan subjek penelitian adalah pasien rawat jalan di Puskesmas Negeri Baru Kabupaten Way Kanan dan penelitian ini telah dilaksanakan pada Bulan Januari sampai dengan Desember Tahun 2019.

HASIL

Tabel 1. Karakteristik Pasien Rawat Jalan di Puskesmas Negeri Baru Kabupaten Way Kanan

\begin{tabular}{lcc}
\hline Variabel & Frekuensi & Persentase \\
\hline Pendidikan & & \\
SD & 26 & 20,31 \\
SMP & 69 & 53,90 \\
SMA & 33 & 25,79 \\
Pekerjaa & & \\
Wiraswasta & 54 & 42,19 \\
Buruh & 67 & 52,34 \\
$\begin{array}{l}\text { PNS } \\
\text { Jenis kelamin }\end{array}$ & 7 & 5,57 \\
Laki-laki & 71 & 55,47 \\
$\begin{array}{l}\text { Perempuan } \\
\text { Kejadian Hipertensi } \\
\text { Hipertensi }\end{array}$ & 57 & 44,53 \\
Tidak Hipertensi & 71 & 55,5 \\
Merokok & 57 & 44,5 \\
Merokok & & \\
\hline
\end{tabular}




\begin{tabular}{lcc}
\hline Variabel & Frekuensi & Persentase \\
\hline Tidak Merokok & 50 & 39,1 \\
Kebiasaan & & \\
Minum Kopi & 83 & 64,8 \\
Tidak minum Kopi & 45 & 35,2 \\
Stress & & \\
Stress & 67 & 52,3 \\
Tidak Stress & 61 & 47,7 \\
\hline
\end{tabular}

Berdasarkan tabel diketahui bahwa karakteristik pendidikan pada pasien rawat jalan di Puskesmas Negeri Baru Kabupaten Way Kanan Tahun 2019, dari 128 responden sebagian besar adalah SMP sebanyak 69 responden (53,90\%).

Diketahui bahwa karakteristik pekerjaan pada pasien rawat jalan di Puskesmas Negeri Baru Kabupaten Way Kanan Tahun 2019, dari 128 responden sebagian besar adalah buruh sebanyak 67 responden (52,34\%). Diketahui bahwa karakteristik pekerjaan pada pasien rawat jalan di Puskesmas Negeri Baru Kabupaten Way Kanan Tahun 2019, dari 128 responden sebagian besar adalah laki-laki sebanyak 71 responden $(55,47 \%)$. Diketahui bahwa kejadian hipertensi pada pasien rawat jalan di Puskesmas Negeri Baru Kabupaten Way Kanan Tahun 2019, dari 128 responden sebagian besar mengalami hipertensi sebanyak 71 responden $(55,5 \%)$ dengan tekanan darah sistolik $\geq 140$ dan dan tekanan diastolik $90 \mathrm{mmHg}$. Diketahui bahwa merokok pada pasien rawat jalan di Puskesmas Negeri Baru Kabupaten Way Kanan Tahun 2019, dari 128 responden sebagian besar berperilaku merokok sebanyak 78 responden $(60,9 \%)$. Diketahui bahwa konsumsi kopi pada pasien rawat jalan di Puskesmas Negeri Baru Kabupaten Way Kanan Tahun 2019, dari 128 responden sebagian besar minum kopi sebanyak 83 responden (64,8\%). Diketahui bahwa stress pada pasien rawat jalan di Puskesmas Negeri Baru Kabupaten Way Kanan Tahun 2019, dari 128 responden sebagian besar mengalami stress sebanyak 67 responden $(52,3 \%)$.

Tabel 2. Analisis Hubungan Perilaku Merokok dengan Kejadian Hipertensi

\begin{tabular}{|c|c|c|c|c|c|c|c|c|}
\hline \multirow{3}{*}{ Merokok } & \multicolumn{4}{|c|}{ Kejadian Hipertensi } & & & \multirow{3}{*}{ P Value } & \multirow{3}{*}{$\begin{array}{c}\text { OR } \\
(95 \% \mathrm{CI})\end{array}$} \\
\hline & \multicolumn{2}{|c|}{ Hipertensi } & \multicolumn{2}{|c|}{$\begin{array}{c}\text { Tidak } \\
\text { Hipertensi }\end{array}$} & \multicolumn{2}{|c|}{ Total } & & \\
\hline & $\mathrm{n}$ & $\%$ & $\mathrm{n}$ & $\%$ & $\mathrm{n}$ & $\%$ & & \\
\hline Merokok & 62 & 79,5 & 16 & 20,5 & 78 & 100 & & 17,653 \\
\hline $\begin{array}{l}\text { Tidak } \\
\text { merokok }\end{array}$ & 9 & 18,0 & 41 & 82,0 & 50 & 100 & $<0,001$ & $\begin{array}{l}(7,127- \\
43,722)\end{array}$ \\
\hline
\end{tabular}

Berdasarkan tabel diketahui bahwa dari 78 responden merokok yang mengalami hipertensi sebanyak 62 responden $(79,5 \%)$, dan 16 responden $(20,5 \%)$ tidak hipertensi. Sedangkan dari 50 responden tidak merokok terdapat 9 responden $(18 \%)$ yang hipertensi, dan 41 responden (82\%) tidak mengalami hipertensi. Hasil uji statistik $p=0,001$ lebih kecil dari nilai alpha $(\alpha=0,05)$ berarti ada hubungan yang bermakna antara merokok dengan kejadian hipertensi pada pasien rawat jalan di Puskesmas Negeri Baru Kabupaten Way Kanan Tahun 2019. Dari hasil analisis diperoleh nilai OR: 17,653. Artinya 
responden yang merokok berisiko hipertensi dibandingkan dengan 17,653 kali lebih besar mengalami responden yang tidak merokok.

Tabel 3. Analisis Hubungan Stress dengan Kejadian Hipertensi

\begin{tabular}{|c|c|c|c|c|c|c|c|c|}
\hline \multirow{3}{*}{ Stress } & \multicolumn{4}{|c|}{ Kejadian Hipertensi } & & & \multirow{3}{*}{ P Value } & \multirow{3}{*}{$\begin{array}{c}\text { OR } \\
(95 \% \mathrm{CI})\end{array}$} \\
\hline & \multicolumn{2}{|c|}{ Hipertensi } & \multicolumn{2}{|c|}{$\begin{array}{c}\text { Tidak } \\
\text { Hipertensi } \\
\end{array}$} & \multicolumn{2}{|c|}{ Total } & & \\
\hline & $\mathrm{n}$ & $\%$ & $\mathrm{n}$ & $\%$ & $\mathrm{n}$ & $\%$ & & \\
\hline Stress & 53 & 80,3 & 13 & 19,7 & 66 & 100 & & 9,996 \\
\hline Tidak Stress & 18 & 29,0 & 44 & 71,0 & 62 & 100 & $<0,001$ & $\begin{array}{l}(4,399- \\
22,576) \\
\end{array}$ \\
\hline
\end{tabular}

Berdasarkan tabel diketahui bahwa dari 66 responden mengalami stress dan yang hipertensi sebanyak 53 responden $(80,3 \%)$, dan 13 responden $(19,7 \%)$ tidak hipertensi. Sedangkan dari 62 responden tidak stress terdapat 18 responden (29\%) yang hipertensi, dan 44 responden (71\%) tidak mengalami hipertensi. Hasil uji statistik $p=0,001$ lebih kecil dari nilai alpha $(\alpha=0,05)$ berarti ada hubungan yang bermakna antara stress dengan kejadian hipertensi pada pasien rawat jalan di Puskesmas Negeri Baru Kabupaten Way Kanan Tahun 2019. Dari hasil analisis diperoleh nilai OR: 9,966. Artinya responden yang mengalami stress berisiko 9,966 kali lebih besar mengalami hipertensi dibandingkan dengan responden yang tidak mengalami stress.

Tabel 4. Analisis Hubungan Konsumsi Kopi dengan Kejadian Hipertensi

\begin{tabular}{|c|c|c|c|c|c|c|c|c|}
\hline \multirow{3}{*}{ Minum Kopi } & \multicolumn{4}{|c|}{ Kejadian Hipertensi } & \multirow{2}{*}{\multicolumn{2}{|c|}{ Total }} & \multirow{3}{*}{$\begin{array}{c}\mathbf{P} \\
\text { Value }\end{array}$} & \multirow{3}{*}{$\begin{array}{c}\text { OR } \\
(95 \% \mathrm{CI})\end{array}$} \\
\hline & \multicolumn{2}{|c|}{ Hipertensi } & \multicolumn{2}{|c|}{$\begin{array}{c}\text { Tidak } \\
\text { Hipertensi }\end{array}$} & & & & \\
\hline & $n$ & $\%$ & $n$ & $\%$ & $\mathrm{n}$ & $\%$ & & \\
\hline Minum kopi & 59 & 71,1 & 24 & 28,9 & 83 & 100 & & 6,760 \\
\hline $\begin{array}{l}\text { Tidak minum } \\
\text { kopi }\end{array}$ & 12 & 26,7 & 33 & 73,3 & 45 & 100 & 0,000 & $\begin{array}{l}(2,997- \\
15,249)\end{array}$ \\
\hline
\end{tabular}

Berdasarkan tabel 4.10 diketahui bahwa dari 83 responden kategori minum kopi dan yang hipertensi sebanyak 59 responden $(71,1 \%)$, dan 24 responden $(28,9 \%)$ yang tidak hipertensi. Sedangkan dari 45 responden tidak minum kopi terdapat 12 responden $(26,7 \%)$ yang hipertensi, dan 33 responden $(73,3 \%)$ tidak mengalami hipertensi. Hasil uji statistik $p=0,001$ lebih kecil dari nilai alpha $(\alpha=0,05)$ berarti ada hubungan yang bermakna antara konsumsi kopi dengan kejadian hipertensi pada pasien rawat jalan di Puskesmas Negeri Baru Kabupaten Way Kanan Tahun 2019. Dari hasil analisis diperoleh nilai OR: 6,760. Artinya responden yang mengkonsumsi kopi berisiko 6,760 kali lebih besar mengalami hipertensi dibandingkan dengan responden yang tidak mengkonsumsi kopi.

\section{PEMBAHASAN}

Kejadian Hipertensi

Berdasarkan hasil dari pengolahan data maka dapat diketahui bahwa kejadian hipertensi pada pasien rawat jalan di Puskesmas Negeri Baru Kabupaten Way Kanan Tahun 2019, dari 128 responden sebagian besar mengalami hipertensi sebanyak 71 responden $(55,5 \%)$.

Hasil penelitian ini didukung teori yang menyatakan bahwa tekanan darah tinggi (hipertensi) adalah suatu peningkatan tekanan darah di dalam 
arteri. (Hiper artinya berlebihan, tensi artinya tekanan/tegangan; jadi, Hipertensi adalah gangguan sistem peredaran darah yang menyebabkan kenaikan tekanan darah diatas normal). Hipertensi didefinisikan oleh Joint National Committee on Detection, Evaluation and Treatment of High Blood Pressure (JIVC) sebagai tekanan yang lebih tinggi dari 140 / $90 \mathrm{mmHg}$ (Sudoyo. AW, 2014).

Hasil penelitian ini didukung oleh penelitian yang dilakukan Rahmawati., Daniyati (2016) tentang hubungan kebiasaan minum kopi terhadap tingkat hipertensi di wilayah kerja Puskesmas Nelayan Kabupaten Gresik. Hasil penelitian menunjukkan bahwa sebagian besar responden yang terkena hipertensi derajat 2 (berat)) sebanyak 55 orang (94.8\%).

Berdasarkan hal tersebut peneliti berpendapat bahwa faktor resiko hipertensi adalah umur, jenis kelamin, riwayat keluarga, genetik (faktor resiko yang tidak dapat diubah/dikontrol), kebiasaan merokok, konsumsi garam, konsumsi lemak jenuh, penggunaan jelantah, kebiasaan konsumsi minum-minuman beralkohol, obesitas, kurang aktifitas fisik, stres, penggunaan estrogen.

\section{Hubungan Merokok Dengan Kejadian Hipertensi}

Hasil uji statistik $p=0,001$ lebih kecil dari nilai alpha $(\alpha=0,05)$ berarti ada hubungan yang bermakna antara merokok dengan kejadian hipertensi pada pasien rawat jalan di Puskesmas Negeri Baru Kabupaten Way Kanan Tahun 2019. Dari hasil analisis diperoleh nilai OR: 17,653. Artinya responden yang merokok berisiko 17,653 kali mengalami hipertensi dibandingkan dengan responden yang tidak merokok.

Hasil penelitian ini sesuai dengan teori yang dikemukakan Muhammadun (2010). menyatakan bahwa selain orang yang merokok (perokok aktif), orang yang tidak merokok tetapi menghisap asap rokok (perokok pasif) juga memiliki resiko hipertensi dua kali dibanding perokok aktif. Nikotin pada perokok secara langsung akan meningkatkan tekanan darah bahkan pada pecandu sekalipun. Efek peningkatan tekanan darah bersifat sementara sekitar 30 menit selama seseorang merokok namun demikian selama pasien merokok tekanan darah tetap meningkat. Merokok $\geq 20$ batang per hari berhubungan erat dengan peningkatan tekanan darah dan hipertrofi ventrikel kiri.

Penelitian terbaru menyatakan bahwa merokok menjadi salah satu resiko hipertensi yang dapat dimodifikasi. Merokok merupakan faktor risiko yang potensial untuk ditiadakan dalam upaya melawan arus peningkatan hipertensi khususnya dan penyakit kardiovaskuler secara umum (Wulandari, 2011).

Hasil penelitian ini didukung oleh penelitian yang dilakukan Manggopa., Ratag., Kandou (2017). Hubungan antara kebiasaan merokok dan stres dengan kejadian penyakit hipertensi di Desa Tarabitan Kecamatan Likupang Barat Kabupaten Minahasa Utara. Hasil uji statistik menunjukan bahwa terdapat hubungan antara kebiasaan merokok dengan kejadian hipertensi $(p=0,000)$.

Hasil tabulasi silang diketahui bahawa dari 78 responden berperilaku merokok sebanyak 16 responden $(20,5 \%)$ yang tidak hipertensi. Hal ini dikarenakan faktor usia responden tersebut dan faktor kebiasan berolah raga sehingga responden tersebut tidak mengalami hipertensi serta dari hasil kuesioner jumlah konsumsi rokok kurang dari 10 batang/hari. Sedangkan dari 50 responden tidak merokok terdapat 9 responden (18\%) yang hipertensi, hal ini dikarenakan faktor genetik dari hasil wawancara diketahui terdapat faktor keturunan pada responden tersebut serta 5 
responden diantaranya mengalami obesitas hal ini yang memicu terjadinya hipertensi

Berdasarkan hasil observasi dan wawancara yang dilakukan dengan responden dengan kategori perokok diantaranya merokok setiap hari dan memiliki kebiasaan merokok lebih dari 20 batang perhari, dan merokok sudah lebih dari 6 bulan. Oleh karena itu perlu adanya kesadaran dari responden itu sendiri untuk menerapkan perilaku hidup sehat dengan tidak merokok secara berlebihan agar terhindar dari penyakit hipertensi.

Berdasarkan hal tersebut peneliti berpendapat bahwa nikotin pada rokok dapat mengakibatkan gangguan pada jantung, mempercepat aliran darah, irama jantung tidak teratur, kerusakan pada pembuluh darah, dan penggumpalan darah. Selain orang yang merokok (perokok aktif), orang yang tidak merokok tetapi menghisap asap rokok juga memiliki resiko hipertensi, orang ini disebut perokok pasif. Dengan resiko dua kali dari perokok aktif.

\section{Hubungan Stress Dengan Kejadian Hipertensi}

Hasil uji statistik $p=0,001$ lebih kecil dari nilai alpha $(\alpha=0,05)$ berarti ada hubungan yang bermakna antara stress dengan kejadian hipertensi pada pasien rawat jalan di Puskesmas Negeri Baru Kabupaten Way Kanan Tahun 2019. Dari hasil analisis diperoleh nilai OR: 9,966. Artinya responden yang mengalami stress berisiko 9,966 kali mengalami hipertensi dibandingkan dengan responden yang tidak mengalami stress.

Menurut Priyoto (2014) kondisi stres dapat disebabkan oleh berbagai penyebab atau sumber, dalam istilah yang lebih umum disebut stresor. Stresor adalah keadaan atau situasi, objek atau individu yang dapat menimbulkan stres.Penelitian ini sejalan dengan penelitian yang dilakukan

Stres akan meningkatkan resistensi pembuluh darah perifer dan curah jantung sehingga akan menstimulasi aktivitas saraf simpatik. Stres ini dapat berhubungan dengan pekerjaan, sosial ekonomi dan karakteristik personal. Stres merupakan respon tubuh yang sifatnya nonspesifik terhadap setiap tuntutan beban atasnya. Terdapat jenis penyakit yang berhubungan dengan stres yang dialami seseorang diantaranya hipertensi (Wulandari, 2011).

Penelitian yang dilakukan Andria (2014) hubungan antara perilaku olahraga, stress dan pola makan dengan tingkat hipertensi pada lanjut usia di Posyandu Lansia Kelurahan Gebang Putih Kecamatan Sukolilo Kota Surabaya. diperoleh $p=0,000$ ( $p<$ $0,05)$ untuk perilaku olahraga dan $p=$ $0,047$ ( $p<0,05)$ untuk perilaku stres. Kesimpulannya adalah ada hubungan antara perilaku olahraga dan stres dengan tingkat hipertensi pada lansia.

Peneliti berasumsi bahwa stres sangat erat hubungannya dengan hipertensi. Stres merupakan masalah yang memicu terjadinya hipertensi dimana hubungan antara stres dengan hipertensi melalui aktivitas saraf simpatis peningkatan saraf dapat menaikkan tekanan darah. Stres yang berkepanjangan dapat mengakibatkan tekanan darah menetap tinggi. Stres berkaitan dengan adanya perubahan yang meliputi perubahan fisiologik, kondisi pisikologik maupun tekanan lingkungan.

Hasil tabulasi silang diketahui bahwa dari 66 responden mengalami stress sebanyak 13 responden $(19,7 \%)$ tidak hipertensi, hal ini dikarenakan beberapa faktor salah satunya adalah pola istirahat tidur yang cukup. Pola istirahat tidur yang baik akan menghindari terjadinya stress. Stres tidak menyebabkan hipertensi yang 
menetap, tetapi stress berat dapat menyebabkan kenaikan tekanan darah yang bersifat sementara yang sangat tinggi. Sedangkan dari 62 responden tidak stress terdapat 18 responden (29\%) yang hipertensi, hal ini dikarenakan faktor usia responden tersebut yaitu rata-rata 50 tahun s/d 60 tahun, diit garam yang berlebihan serta faktor keturunan pada responden tersebut.

\section{Hubungan Konsumsi Kopi Dengan Kejadian Hipertensi}

Hasil uji statistik $p=0,001$ lebih kecil dari nilai alpha $(\alpha=0,05)$ berarti ada hubungan yang bermakna antara konsumsi kopi dengan kejadian hipertensi pada pasien rawat jalan di Puskesmas Negeri Baru Kabupaten Way Kanan Tahun 2019. Dari hasil analisis diperoleh nilai OR: 6,760. Artinya responden yang mengkonsumsi kopi berisiko 6,760 kali mengalami hipertensi dibandingkan dengan responden yang tidak mengkonsumsi kopi.

Menurut Wulandari

menyatakan bahwa konsumsi kopi yang berlebihan dalam jangka yang panjang dan jumlah yang banyak diketahui dapat meningkatkan risiko penyakit. Hipertensi atau penyakit Kardiovaskuler. Beberapa penelitian menunjukan bahwa orang yang mengkonsumsi kafein (kopi) secara teratur sepanjang hari mempunyai tekanan darah rata-rata lebih tinggi dibandingkan dengan didalam 2-3 gelas kopi (200-250 mg) terbukti meningkatkan tekanan sistolik sebesar 3-14 $\mathrm{mmHg}$ dan tekanan diastolik sebesar 4-13 $\mathrm{mmHg}$ pada orang yang tidak mempunyai hipertensi.

Mengkonsumsi kafein secara teratur sepanjang hari mempunyai tekanan darah rata-rata lebih tinggi di bandingkan dengan kalau mereka tidak mengkonsumsi sama sekali. Kebiasaan mengkonsumsi kopi dapat meningkatkan kadar kolesterol darah dan meningkatkan risiko terkena penyakit jantung (Sustrani, 2013).

Hasil penelitian ini didukung oleh penelitian yang dilakukan Rahmawati., Daniyati (2016) tentang hubungan kebiasaan minum kopi terhadap tingkat hipertensi di wilayah kerja Puskesmas Nelayan Kabupaten Gresik. Hasil penelitian didapatkan nilai signifikan (2-tailed) $=0,000$ yang berarti ada hubungan kebiasaan minum kopi terhadap tingkat hipertensi, sedangkan nilai korelasi $r=$ 0,809 artinya ada derajat hubungan sangat kuat antara kebiasaan minum kopi terhadap tingkat hipertensi.

Hasil tabulasi silang diketahui bahwa dari 83 responden dengan perilaku peminum kopi sebanyak 24 responden $(28,9 \%)$ yang tidak hipertensi. Hal ini dikarenakan faktor lain yang mempengaruhi pada responden tersebut yang berpengaruh pada kejadian hipertensi hasil jawaban kuesioner pada pertanyaan tentang lama kebiasaan minum kopi yaitu kurang dari 6 bulan, sesuai teori kafein pada tubuh manusia dapat mentolerir kafein yang di minum seseorang setiap harinya dan dalam jangka waktu panjang. Sedangkan dari 45 responden bukan peminum kopi terdapat 12 responden $(26,7 \%)$ yang hipertensi, hal ini dikarenakan faktor stress yang dialami responden tersebut serta konsumsi garam yang berlebihan.

Berdasarkan hal tersebut peneliti berpendapat bahwa kopi adalah bahan minuman yang banyak mengandung kafein. Kopi juga berakibat buruk pada jantung. Kafein dapat menstimulasi jantung untuk bekerja lebih cepat sehingga mengalirkan lebih banyak cairan

\section{KESIMPULAN}

Ada hubungan merokok, minum kopi, stress dengan kejadian hipertensi pada pasien rawat jalan di Puskesmas 
Negeri Baru Kabupaten Way Kanan Tahun 2019.

\section{SARAN}

Untuk responden yang mengkonsumsi kopi disarankan agar mengurangi konsumsi kopi dengan cara mengurangi dosis atau takaran kopi dan gula. Serta disarankan bagi responden yang merokok untuk mengurangi jumlah rokok yang dihisap secara bertahap. Bagi responden yang mengalami stres sebaiknya untuk memeriksakan kesehatan secara rutin. Diharapkan untuk dapat meningkatkan upaya promotif melalui penyuluhan kesehatan yang bertujuan menyampaikan informasi bagaimana cara pencegahan hipertensi secara jelas. Memberikan media informasi seperti leaflet, poster dll, agar semua lapisan masyarakat dapat tersentuh dengan informasi tentang hipertensi. Diharapkan dengan penelitian ini dapat menjadi bahan masukan dan pengembangan penelitian berikutnya untuk melanjutkan penelitian serta meneliti variabel lain yang berbeda seperti meneliti tingkat sosial ekonomi, olah raga,konsumsi garam serta akses pelayanan kesehatan yang berhubungan dengan kejadian hipertensi.

\section{DAFTAR PUSTAKA}

Andria. (2014). Hubungan perilaku olahraga, stress dan pola makan dengan tingkat hipertensi pada lanjut usia di Posyandu Lansia Kelurahan Gebang Putih Kecamatan Sukolilo Kota Surabaya. Jurnal Promkes, Vol. 1, No. 2 Desember 2013: 111-117.

Aspiani, Reny Yuli. (2014). Buku Ajar Asuhan Keperawatan Gerontik. Aplikasi Nanda NIC Dan NOC. Jakarta: Trans Info Media.

Dahlan, MS. (2011). Statistik Untuk Kedokteran Dan Kesehatan. Jakarta: Salemba medika.
Dinas Kesehatan Provinsi Lampung. (2017). Profil Kesehatan Provinsi Lampung. Bandar Lampung.

Hastono, Sutanto Priyo. (2017). Analisis Data Pada Bidang Kesehatan. Depok: Raja Grafindo Persada.

Kementrian Kesehatan Republik Indonesia. (2018). Profil Kesehatan Indonesia. Katalog Dalam Terbitan. Jakarta: Kementerian Kesehatan Republik Indonesia.

Kementrian Kesehatan Republik Indonesia. (2014). Infodatin. Pusat data dan Informasi. Hipertensi. Jakarta: Kementerian Kesehatan Republik Indonesia.

Manggopa., Ratag., Kandou (2017). Hubungan antara kebiasaan merokok dan stres dengan kejadian penyakit hipertensi di Desa Tarabitan Kecamatan Likupang Barat Kabupaten Minahasa Utara. KESMAS, 6(3). Fakultas Kesehatan Masyarakat Universitas Sam Ratulangi Manado https://ejournal.unsrat.ac.id/index. php/kesmas/issue/view/2197

Muhammadun, AS. (2010). Hidup Bersama Hipertensi Seringai Darah Tinggi Sang Pembunuh Sekejap. Jogjakarta: In-books.

Notoatmodjo, S. (2014). Metodologi Penelitian Kesehatan. Jakarta: Penerbit PT. Rineka Cipta.

Notoatmodjo, S. (2014). Ilmu Perilaku Kesehatan. Jakarta: Penerbit PT. Rineka Cipta.

Nurarif, Amin. Huda., Kusuma. Hardi. (2015). Aplikasi Asuhan Keperawatan Medis Dan Nanda. (Nort American Nursing Diagnosis Association). NIC-NOC. Panduan Penyusunan Asuhan Keperawatan Profesional. Edisi Revisi. Jilid 2.Yogyakarta: Medi Action.

Nursalam. (2013). Konsep Dan Penerapan Metodelogi Penelitian IImu Keperawatan: Aplikasi dalam Praktik Keperawatan Profesional, Edisi 4. Jakarta: Salemba Medika. 
Priyoto. (2014). Konsep Manajemen stres. Yogyakarta: Nuha Medika.

Rahmawati., Daniyati. (2016). Hubungan kebiasaan minum kopi terhadap tingkat hipertensi di wilayah kerja Puskesmas Nelayan Kabupaten Gresik. Journals of Community. Volume 07, Nomor 02, November 2016. Hal. 149-161

Rhomandhon. (2014). Manajemen Pikiran Untuk Mengatasi Stress, Depresi, Kemarahan Dan Kecemasan. Yogyakarta: Pradipta Sarastika.

Riyanto, Agus. (2011). Aplikasi Metodelogi Penelitian Kesehatan. Yogyakarta: Nuha Medika.

Sudoyo, Aru. W. (2014). Buku Ajar Ilmu Penyakit Dalam. Jilid III Edisi VI. Jakarta: Interna Publishing.

Sustrani. L, dkk. (2009). Hipertensi. Jakarta : PT. Gramedia Pustaka Utama

Sutanto. (2010). Cekal Penyakit Modern Hipertensi, Stroke, Jantung, Kolesterol Dan Diabetes. Gejala-Gejala Pencegahan Dan Pengendalian. Jogjakarta: Andi.

Suyanto. (2011). Metodelogi dan Aplikasi Penelitian Keperawatan. Yogyakarta: Nuha Medika.

Wijayaningsih. (2013). Standar Asuhan Keperawatan. Jakarta: Trans Info Media.

Wulandari. A. \& Susilo. Y. (2011). Cara jitu mengatasi hipertensi. Jogjakarta: Andi: 